\title{
ABALOS SÍSMICOS MODERADOS NO BRASIL: UM LEVANTAMENTO DOS EVENTOS REGISTRADOS NOS SÉCULOS XX E XXI E A DIFUSÃO DE MEDIDAS PREVENTIVAS
}

\author{
Willian Sartor Preve ${ }^{(a)}$, Giovana Pereira Carraro D’Espindula ${ }^{(b)}$, Jairo Valdati ${ }^{(c)}$ \\ (a) Graduando do curso de Geografia - Bacharelado, Universidade do Estado de Santa Catarina, \\ williansartor@gmail.com \\ (b) Graduanda do curso de Geografia - Licenciatura, Universidade do Estado de Santa Catarina, \\ gp.carraro07@gmail.com \\ (c) Professor do Curso de Geografia, Departamento de Geografia, Universidade do Estado de Santa Catarina, \\ javaldati@hotmail.com
}

\section{Eixo: GEOGRAFIA FÍSICA E DESASTRES NATURAIS}

\begin{abstract}
Resumo
O artigo tem por objetivo apresentar a ocorrência de terremotos de magnitude moderada no território nacional, o qual efetuou-se através de um levantamento dos eventos de magnitude $\geq 5 \mathrm{Mb}$. Para atingir nosso escopo, realizou-se, primeiramente, uma caracterização dos terremotos seguido de uma abordagem das falhas neotectônicas, que são os mecanismos desencadeadores dos tremores brasileiros. Ademais,-abordou-se o nível de atividade sísmica, a implantação da Rede Sismográfica Brasileira e a NBR 15421 da Associação Brasileira de Normas Técnicas para a construção civil, finalizado com as Cartilhas de Prevenção de Desastres propostas pelas Secretarias Estaduais de Defesa Civil. Concluímos que esses eventos vêm ocorrendo majoritariamente na região Norte, porém o caso de Itacarambi-MG mostra que um sismo moderado (aproximadamente 4,9) causou destruição e a primeira vítima fatal no Brasil. Desse modo,-sugerimos o uso de instrumentos como Cartilhas para as comunidades e as redes escolares, com a finalidade de alertar sobre o tema.
\end{abstract}

Palavras chave: Abalos Sísmicos; Terremotos no Brasil; Falhas Neotectônicas; Secretarias Estaduais de Defesa Civil.

\section{INTRODUÇÃO}

A preocupação com a temática dos abalos sísmicos não é recente, pois o terremoto que devastou a cidade de Lisboa em 1755 foi motivo de discussão para filósofos como Voltaire e Rousseau (VALDATI, 2000). Sabe-se também que os terremotos são um dos fenômenos mais destrutivos da natureza, sendo que no século XX cerca de 2,7 milhões de pessoas morreram em consequências deles (WICANDER, 2009).

O tremor de maior magnitude já registrado pela humanidade aconteceu no ano de 1960 no Chile, alcançando 9,5 graus na Escala Magnitude de Momento $(\mathrm{Mw})^{1}$ e é conhecido como "O Grande Sismo do

\footnotetext{
${ }^{1}$ A Escala de Momento (Mw) é usada para medir a magnitude de um terremoto, ao levar em consideração a área da falha, o deslocamento e a resistência das rochas, ela representa a melhor estimativa da verdadeira magnitude do terremoto (INGV, 2017).
} 
Chile" (PENA, 2016). A recorrentemente discussão sobre os tremores de terra toma corpo na sociedade devido a cobertura midiática global, assim o ano de 2016 foi marcado pela onda de terremotos que atingiu a região central da Itália e causou a perda de aproximadamente 300 vidas. Dentro de um outro contexto sísmico, um tremor de magnitude 4,7 atingiu o Estado do Maranhão no início de 2017, causando o evacuamento de prédios e evidenciando um plausível despreparo da população em relação a esse tipo de evento.

Considerando que cerca de $95 \%$ dos terremotos se sucedem nas áreas limítrofes de placas tectônicas (WICANDER, 2009) e que o Brasil está situado na parte central da placa Sul-Americana, os terremotos de grande magnitude, teoricamente, não ocorreriam. Entretanto, o escopo deste artigo, é apresentar a ocorrência de eventos de magnitude moderada no território nacional, algo que encontra respaldo na recente instalação da Rede Sismográfica Brasileira (RSBR) e na Norma Técnica (NBR) 15.421/2006, que fixa os requisitos mínimos de segurança das estruturas na construção civil, quaisquer que sejam sua classe e função.

Dentro da temática dos perigos geoambientais, este trabalho tem por objetivo realizar um levantamento dos terremotos de magnitude superior ou igual a $5 \mathrm{Mb}^{2}$, ocorridos em território brasileiro durante todo o século XX e XXI e investigar as informações/direcionamentos que as Secretarias Estaduais da Defesa Civil disponibilizam para a população em resposta a este evento. Para tal fim, inicia-se o artigo contextualizando a sismicidade, conceituando-se o fenômeno sísmico, destaca-se as principais causas dos tremores no Brasil, em seguida apresenta-se o nível de atividade sísmica no país e por fim, o levantamento dos registros de sismos com magnitude superior ou igual a 5 no território nacional e as informações que concernem as Cartilhas de Prevenção.

\section{MATERIAIS E MÉTODOS}

A metodologia utilizada para a elaboração deste artigo foram pesquisas em livros e artigos científicos acerca dos abalos sísmicos que ocorrem em todo o território nacional, assim como o estudo da NBR 15.421/2006. Sites da internet também serviram de apoio, principalmente os que informam os dados de redes sismológicas. Essas pesquisas foram realizadas entre os meses de setembro de 2016 e fevereiro de 2017.

\footnotetext{
${ }^{2}$ A fonte de dados utilizada para a elaboração do levantamento fornece os valores na escala de Magnitude de Ondas de Corpo $(\mathrm{Mb})$, que, apesar de produzir valores aproximados às demais escalas (USGS, 2016), geralmente é a mais rápida a ser calculada pois leva em consideração o deslocamento da onda P (mais veloz) (WOO, 2012).
} 


\section{CARACTERIZAÇÃO DO FENÔMENO}

Ao abordar a temática dos perigos geoambientais, no qual se insere o fenômeno dos terremotos, é importante ressaltar que o país não conta com um histórico de eventos de elevada magnitude. Todavia, a qualidade das estruturas deve ser considerada, dada a sua relação com o fator de vulnerabilidade socioeconômica de boa parte da população brasileira, bem como o desconhecimento da população para com a sismicidade, o que potencializa os danos e possibilita a geração de desastres durante e após a ocorrência de sismos de magnitude moderada.

O conceito de perigo (ou ameaça) é definido por Palacios (2005, p. 11) como a probabilidade de ocorrência de um fenômeno natural ou induzido pela atividade humana potencialmente danoso a uma localidade ou território. Segundo a classificação proposta por Cerri e Amaral (1998, p. 302), há 03 (três) categorias de perigos: os tecnológicos, naturais e os sociais. O perigo de ocorrência de terremotos, de acordo com a classificação proposta, enquadra-se como perigo geológico de origem endógena.

Wicander (2009, p. 185) define o terremoto "como um abalo ou tremor causado pela liberação repentina de energia, normalmente como resultado da falha que envolve o deslocamento das rochas". Após o terremoto podem ocorrer diversos abalos secundários, na maioria das vezes menor que o tremor principal, mas podendo ocasionar danos às estruturas já debilitadas. É importante destacar que apesar de ocorrerem majoritariamente nos limites de placas tectônicas, devido a energia gerada pelo movimento dessas, os terremotos podem anteceder atividades vulcânicas e também serem causados por diversos tipos de falhas, tal como as falhas neotectônicas.

As rochas nas zonas de falhas - que são áreas suscetíveis à ocorrência de terremotos - são deformadas devido à ação de uma determinada tensão, normalmente gerada a partir do movimento das placas tectônicas. De acordo com sua resistência, as rochas acumulam a tensão até determinados limites inerentes às suas características físicas, rompendo-se quando sua resistência é superada. A partir de então, ocorre uma liberação de energia que se transforma em ondas sísmicas, sendo essas ondas produzidas a partir do ponto onde a ruptura se inicia. O hipocentro ou foco é a posição na qual ocorreu a ruptura, localizando-se sempre em profundidade, já o epicentro é a localização geográfica na superfície terrestre sobre o foco. A profundidade focal é a distância entre a superfície da Terra ao foco. 


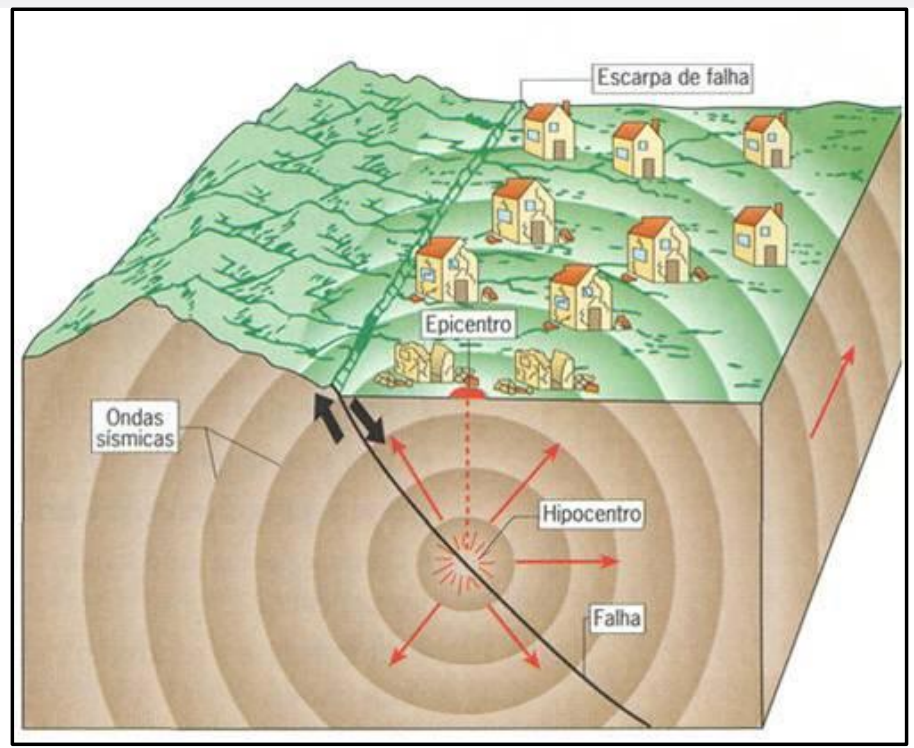

Figura 01: Esquema de Hipocentro e Epicentro. Fonte: Simões, 2013.

Os terremotos são geralmente mensurados em duas categorias: a de intensidade e de magnitude. A intensidade está relacionada às perdas e danos de um abalo sísmico, enquanto a magnitude relaciona-se com a quantidade de energia liberado pelo evento.

A magnitude de um tremor de terra é um valor que representa a quantidade de energia liberada. A Escala de Magnitude Richter, que é frequentemente utilizada, é uma escala logarítmica que não possui limites de valores, começando por 01 (um) e na qual cada número inteiro na escala corresponde a um aumento aproximado de 30 vezes na quantidade de energia liberada, limitando-se à medição do pico mais alto de energia liberado no tremor de terra.

Segundo Lopes e Nunes (2011), a Escala de Intensidade Sísmica mais comum no ocidente é a Escala Mercalli Modificada (MM) (tabela 01), que é dada em algarismos romanos. As companhias de seguro classificam os terremotos com base na intensidade, dado que esta é uma medida que se baseia nos danos causados. Diversos fatores auxiliam na formação da escala: a distância do epicentro, a profundidade focal do terremoto, a densidade populacional, a geologia local da área, o tipo de construção das edificações e a duração dos terremotos (WICANDER, 2009).

Tabela 01: Escala de Mercalli

\begin{tabular}{|c|l|}
\hline $\begin{array}{c}\text { Escala Mercalli } \\
\text { Modificada }\end{array}$ & \multicolumn{1}{c|}{ Descrição do nível de intensidade } \\
\hline I & $\begin{array}{l}\text { Não sentido pelas pessoas, sendo registrado apenas pelos sismógrafos, exceto em } \\
\text { condições extremamente favoráveis. }\end{array}$ \\
\hline II & Sentido apenas por algumas pessoas, especialmente em prédios altos. \\
\hline
\end{tabular}




\begin{tabular}{|c|c|}
\hline \multirow{2}{*}{$\begin{array}{l}\text { XVII Simpósio Brasileiro } \\
\text { de Geografia Fisica Aplicada } \\
\text { I Congresso Nacional } \\
\text { de Geografia Física }\end{array}$} & \multirow{2}{*}{$\begin{array}{l}\text { OS DESAFIOS DA GEOGRAFIA FÍSICA NA FRONTEIRA DO CONHECIMENTO } \\
\text { Instituto de Geociências - Unicamp } \\
\text { Campinas - SP } \\
28 \text { de Junho à 02 de Julho de } 2017\end{array}$} \\
\hline & \\
\hline III & $\begin{array}{l}\text { É sentido por algumas pessoas em casa, especialmente nos andares superiores em } \\
\text { prédios altos. Pode não ser reconhecido como um abalo sísmico. }\end{array}$ \\
\hline IV & 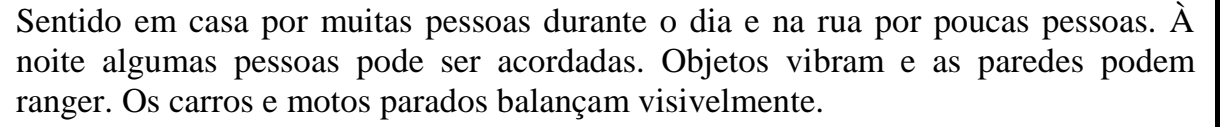 \\
\hline $\mathrm{V}$ & $\begin{array}{l}\text { Sentido por praticamente todas as pessoas, muitos são acordados. As pessoas } \\
\text { conseguem identificar a direção do movimento. Objetos pequenos e instáveis são } \\
\text { deslocados. Portas oscilam, fecham, abrem. }\end{array}$ \\
\hline VI & $\begin{array}{l}\text { Sentido por todas as pessoas, muitos devido ao medo saem às ruas. Algumas } \\
\text { mobílias pesadas podem se movimentar. Objetos caem de prateleiras. Ocorrência de } \\
\text { danos moderados em estruturas de má qualidade. }\end{array}$ \\
\hline VII & $\begin{array}{l}\text { Sentido inclusive por pessoas que estão dirigindo automóveis. Ocorrência de danos } \\
\text { pequenos em edifícios bem construídos, danos moderados em casas bem construídas } \\
\text { e danos consideráveis em estruturas mal construídas. Algumas chaminés se } \\
\text { quebram. Pequenos escorregamentos de barrancos arenosos. }\end{array}$ \\
\hline VIII & $\begin{array}{l}\text { Danos em construções normais, inclusive com colapso parcial. Algum dano em } \\
\text { construções especialmente projetadas. Queda de muros de alvenaria, chaminés, } \\
\text { monumentos, torres e caixas d'água. Trincas no chão. }\end{array}$ \\
\hline IX & $\begin{array}{l}\text { Pânico generalizado. Construções comuns muito danificadas, às vezes colapso total. } \\
\text { Danos consideráveis em construções especialmente projetadas e em grandes } \\
\text { edifícios, com colapso parcial. Tubulação subterrânea quebrada. Rachaduras visíveis } \\
\text { no solo. }\end{array}$ \\
\hline$X$ & $\begin{array}{l}\text { Maioria das construções destruídas inclusive nas fundações. Danos sérios a } \\
\text { barragens e diques. Terra desliza consideravelmente. Trilhos levemente entortados. } \\
\text { A água molha as margens dos rios. }\end{array}$ \\
\hline XI & $\begin{array}{l}\text { Poucas estruturas de alvenaria não colapsam totalmente. Pontes são destruídas e os } \\
\text { trilhos dos trens são completamente entortados. As tubulações subterrâneas são } \\
\text { completamente destruídas. }\end{array}$ \\
\hline XII & $\begin{array}{l}\text { Destruição quase total. A paisagem é modificada com a topografia sendo distorcida. } \\
\text { Grandes blocos de rocha são deslocados. Objetos são jogados ao ar. Essa } \\
\text { intensidade nunca foi observada no período histórico. }\end{array}$ \\
\hline
\end{tabular}

\section{AS FALHAS NEOTECTÔNICAS E A ATIVIDADE SÍSMICA NO BRASIL}

\subsection{AS FALHAS NEOTECTÔNICAS}

Conforme já constatado, não podemos descartar a ocorrência de significativos tremores no território nacional. De acordo com Saadi (1993), os abalos que ocorrem no país são principalmente devidos às várias falhas neotectônicas encontradas no Brasil. O termo neotectônica foi apresentado por Obruchev (1948, apud HIRUMA, RICCOMINI E MODENESI-GAUTTIERI, 2001, p. 4) com o intuito de "designar movimentos tectônicos recentes, ocorridos no fim do Terciário e início do Quaternário, que tiveram papel decisivo na formação da topografia contemporânea”.

Pavlides (1984, apud SAADI, 1993, p. 2) afirma que o "início do período tectônico depende das 




características individuais, de cada ambiente geológico, sendo que o objeto da Neotectônica é o estudo de eventos tectônicos novos, que ocorreram ou estão ocorrendo após a orogênese final [...]”. Em conformidade com Saadi (1993, p. 2), segundo o qual a Comissão de Neotectônica da Associação Internacional de Estudos do Quaternário (INQUA) postulou a ausência de limites temporais, podendo ser considerados eventos neotectônicos desde aqueles momentâneos até os de idade acima de $10^{\underline{z}}$-anos, caso necessário. Assim, no território brasileiro, as falhas neotectônicas são aquelas que ocorreram após o último evento orogênico (SAADI, 1993).

Em um trabalho que delineia um panorama sobre as principais características neotectônicas regionais da plataforma continental brasileira, Saadi discorre que o país possui um total de 48 falhas, com maior número nas regiões Sudeste e Nordeste, seguidos das regiões Norte e Centro-Oeste e com poucas falhas na região no Sul, conforme figura 02.

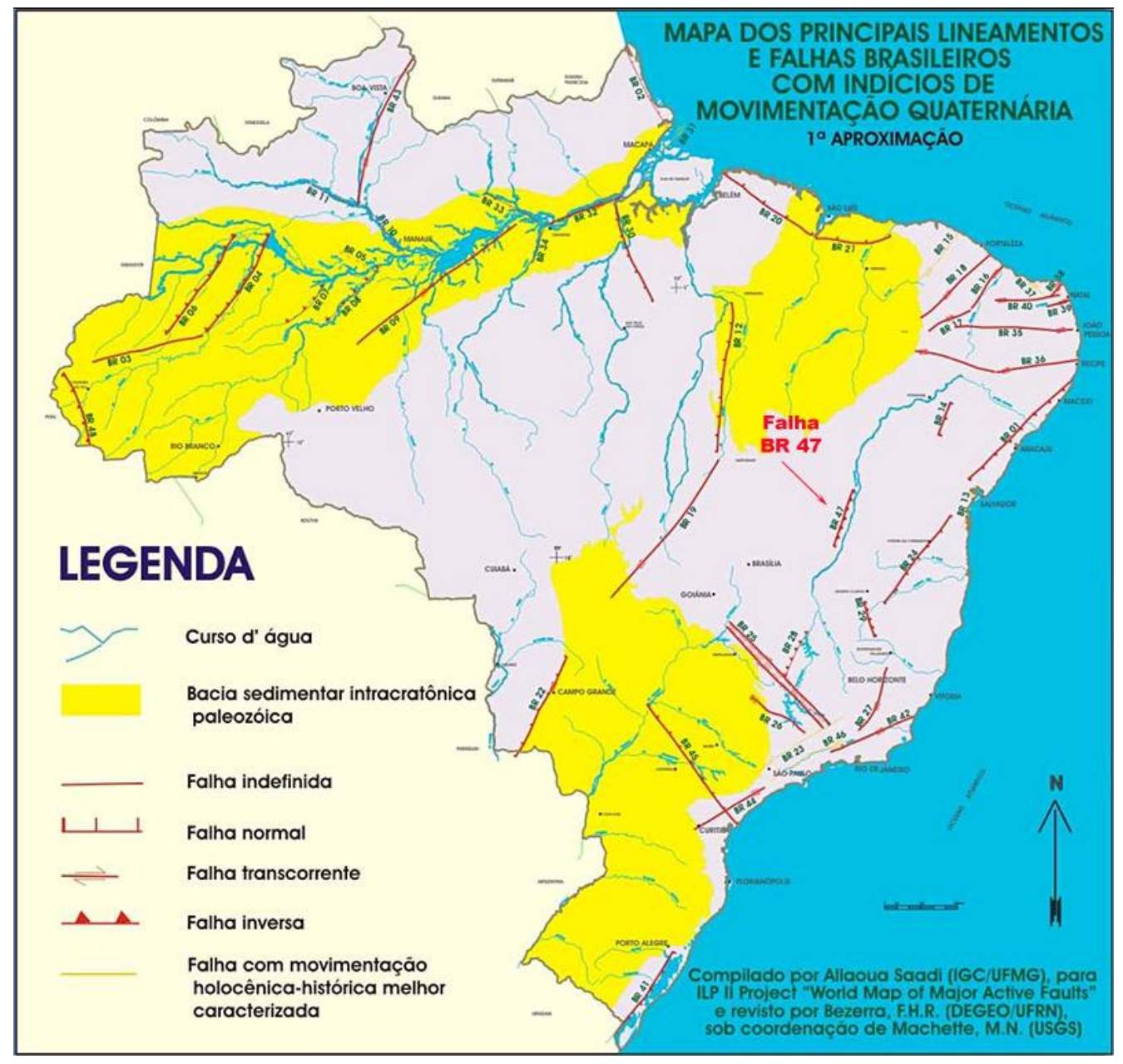

Figura 02: Mapa dos principais lineamentos e falhas brasileiras, dando destaque a falha BR 47, sobre a qual ocorreu o sismo de Itacarambi, em 2007. Fonte: Apolo11, 2007.

\subsection{A ATIVIDADE SÍSMICA NO BRASIL}


O nível de atividade sísmica no Brasil caracteriza-se pela "ocorrência média de menos de dois sismos com magnitudes maiores que 4 por ano, um sismo com magnitude maior que 5 a cada seis anos, e um sismo de magnitude 6 a cada 45 anos" (LOPES E NUNES, 2011, p. 90). Embora se possa qualificar como nível baixo, a ação dos sismos no país deve ser considerada como potencialmente danosa caso ocorra próximo a centros urbanos e grandes obras de engenharia, pois os maiores sismos registrados no Brasil aconteceram relativamente afastados de grandes densidades populacionais, não causando grandes danos.

Lopes e Nunes (2011) elaboram, em um artigo, cenários sísmicos no país e as consequências, caso algum tremor de magnitude e intensidade moderada atinja municípios densamente povoados ou grandes obras, como o município de São Paulo ou usinas hidrelétricas respectivamente. Reconhecem que uma atividade sísmica com magnitude próxima de 6 é um evento raro, entretanto caso ocorra a uma distância de até 50 km de uma barragem, por exemplo, além do seu potencial de destruição, ocasionaria intensidade próxima de VII em um raio de $50 \mathrm{~km}$ e VIII para $25 \mathrm{~km}$ (vide Tabela 01).

É relevante ressaltar que o estudo da sismologia no país já encontra respaldo em uma normativa técnica da Associação Brasileira de Normas Técnicas - ABNT referente à construção de estruturas resistentes a sismos e na instalação da Rede Sismográfica Brasileira (RSBR). A RSBR é originária de parcerias entre algumas universidades e a Petrobras, com financiamento desta última, sendo que atualmente conta com 91 estações instaladas no país ${ }^{3}$. No que se refere à construção civil, a NBR 15.421 (ASSOCIAÇÃO BRASILEIRA DE NORMAS TÉCNICAS, 2006) estabelece requisitos mínimos para estruturas usuais da construção civil no que compete a ação dos terremotos, cabendo ressaltar que não é aplicável a estruturas especiais tais como pontes, viadutos, obras hidráulicas e torres.

No âmbito da NBR 15.421, o Brasil é dividido em cinco regiões sísmicas, sendo que é um zoneamento de acordo com a variação da aceleração sísmica horizontal, como se pode observar na figura 03. Assim, estabelece-se que a Zona 0 e a Zona 4 são as áreas que apresentam o menor e o maior perigo, respectivamente. A Zona 0 , a qual abrange maior área do país, é a única a não exigir nenhum requisito de resistência a terremotos.

\footnotetext{
${ }^{3}$ Sendo que 03 (três) destas se localizam no Estado de Santa Catarina, nas cidades de Itá, Major Gercino e Treze de Maio, e esta última encontra-se nas proximidades de Tubarão. (RSBR, 2017)
} 



Figura 03: Mapa de Sismicidade do Brasil. Fonte: Lopes e Nunes, 2011.

Lopes e Nunes (2011, p. 97) afirmam que, apesar de o país contar com uma norma relativamente adequada, a mesma não está em conformidade com o padrão de ocorrência dos sismos, pois a norma foi elaborada com base em um mapa de perigo sísmico mundial. Em consonância com os autores, há a recomendação de atualizar a norma sísmica brasileira de acordo com os mapas de perigo regionais (DEFESA CIVIL, 2008).

A falta de representatividade deste mapa é comprovada pela constatação de que a maior parte dos casos já registrados no país localizam-se na Zona 0 , inclusive o sismo que atingiu o município de Itacarambi/MG, no ano de 2007 e que gerou a primeira fatalidade no Brasil e o de Tubarão em 1939, com magnitude de 5,5, que ocorreu na plataforma continental oceânica, a cerca de $200 \mathrm{~km}$ da costa.

\section{LEVANTAMENTO DE SISMOS MODERADOS NO BRASIL E A PROPOSIÇÃO DE CARTILHAS DE PREVENÇÃO PELA DEFESA CIVIL}

O levantamento realizado diz respeito aos tremores de magnitude igual ou superior a $5 \mathrm{Mb}$ ocorridos nos séculos XX e XXI em território nacional, cujos dados foram obtidos no site do Observatório Sismológico da Universidade de Brasília (OBSIS, 2016). Ao analisar a tabela, é relevante destacar que o aumento do 
número de eventos registrados, principalmente após o ano de 1990, é devido, sobretudo, à instalação de novos sismógrafos no país, passando a abranger maior área, e a elevação dos casos percebida na última década é resultado da instalação da RSBR. Ressalta-se que os dados mais antigos que foram catalogados não obedeciam aos padrões tecnológicos atuais, portanto, menos precisos.

Tabela 02: Levantamento dos Sismos no Brasil de magnitude superior ou igual a $5 \mathrm{Mb}$

\begin{tabular}{|c|c|c|c|c|c|c|c|c|}
\hline Ano & Localização & $\begin{array}{c}\text { Escala } \\
\text { Mb }\end{array}$ & Ano & Localização & $\begin{array}{c}\text { Escala } \\
\text { Mb }\end{array}$ & Ano & Localização & $\begin{array}{c}\text { Escala } \\
\text { Mb }\end{array}$ \\
\hline 1922 & $\begin{array}{c}\text { Passa } \\
\text { Tempo/MG }\end{array}$ & 5,1 & 1997 & $\begin{array}{l}\text { Atalaia do } \\
\text { Norte/AM }\end{array}$ & 5,4 & 2010 & $\begin{array}{c}\text { Mara } \\
\text { Rosa/GO }\end{array}$ & 5,0 \\
\hline 1939 & Tubarão/SC & 5,5 & 1997 & Feijó/AC & 5,4 & 2012 & Macau/RN & 5,3 \\
\hline 1949 & Oiapoque/AP & 5,0 & 1998 & $\begin{array}{c}\text { Porto do } \\
\text { Gaúchos/MT }\end{array}$ & 5,2 & 2012 & $\begin{array}{c}\text { São } \\
\text { Caitano/PE }\end{array}$ & 5,0 \\
\hline 1955 & $\begin{array}{c}\text { Porto dos } \\
\text { Gaúchos/MT }\end{array}$ & 6,2 & 1998 & Tarauacá/AC & 5,4 & 2013 & Jordão/AC & 5,0 \\
\hline 1955 & Vitória/ES & 6,1 & 1998 & Tarauacá/AC & 5,5 & 2014 & $\begin{array}{l}\text { Cruzeiro do } \\
\text { Sul/AC }\end{array}$ & 5,1 \\
\hline 1963 & Manaus/AM & 5,1 & 2002 & $\begin{array}{l}\text { Atalaia do } \\
\text { Norte/AM }\end{array}$ & 5,5 & 2014 & $\begin{array}{l}\text { Atalaia do } \\
\text { Norte/AM }\end{array}$ & 5,0 \\
\hline 1983 & Feijó/AC & 5,8 & 2003 & Ipixuma/AM & 7,1 & 2014 & Macapá/AP & 5,4 \\
\hline 1986 & Ipixuma/AM & 5,9 & 2003 & Ipixuma/AM & 5,1 & 2015 & Feijó/AC & 5,1 \\
\hline 1989 & Tarauacá/AC & 6,4 & 2005 & $\begin{array}{c}\text { Porto do } \\
\text { Gaúchos/MT }\end{array}$ & 5,0 & 2015 & Feijó/AC & 6,4 \\
\hline 1989 & $\begin{array}{l}\text { Cruzeiro do } \\
\text { Sul/AC }\end{array}$ & 5,9 & 2007 & Tarauacá/AC & 6,1 & 2015 & Feijó/AC & 5,0 \\
\hline 1990 & Feijó/AC & 5,3 & 2009 & Tarauacá/AC & 5,6 & 2015 & Feijó/AC & 5,3 \\
\hline 1994 & Feijó/AC & 5,8 & 2009 & Tarauacá/AC & 5,4 & 2015 & Feijó/AC & 5,4 \\
\hline 1994 & Feijó/AC & 5,7 & 2010 & $\begin{array}{l}\text { Cruzeiro do } \\
\text { Sul/AC }\end{array}$ & 6,5 & 2015 & Amaturá/AM & 5,4 \\
\hline
\end{tabular}




\begin{tabular}{|l|l|l|l|l|l|l|l|l|}
\hline & & & & & 2016 & $\begin{array}{c}\text { Cruzeiro do } \\
\text { Sul/AC }\end{array}$ & 5,0 \\
\hline
\end{tabular}

Constata-se que há uma concentração destes eventos na região Norte, mais de $70 \%$ do total, seguido pela região Centro Oeste, depois encontram-se a Sudeste e Nordeste e por fim a Região Sul, que conta com apenas um evento. Todavia, o terremoto de magnitude 4,9 (OBSIS, 2017) que teve o epicentro no município de Itacarambi-MG (região Sudeste) em 2007, atingiu severamente um dos bairros mais socioeconomicamente vulneráveis, causando avarias em dezenas de casas, das quais 6 foram completamente destruídas e deixou a primeira vítima fatal desse evento no país (CORONEL PAIM, 2008). Desse modo, instiga-se a adoção de medidas de prevenção em todo o território nacional, principalmente em áreas nas quais a escassez de recursos materiais é maior.

Com o intuito de averiguar como as informações sobre os procedimentos a serem tomados durante a ocorrência de desastres eram disponibilizadas pela Defesa Civil, realizou-se uma pesquisa nos sites Estaduais da Secretaria de Defesa Civil. Constatou-se que são disponibilizadas apenas pelos Estados do Ceará e Maranhão cartilhas que indicam como proceder em caso de desastres naturais, com o perigo de terremoto incluso. A Cartilha apresentada pelo órgão representante do Estado do Ceará inclui a explicação do fenômeno, as escalas de mensuração e por fim as ações que devem ser tomadas antes e durante um evento sísmico. Por sua vez, o órgão representante do Estado do Maranhão aponta as ações a serem executadas logo após o tremor, desde os instantes posteriores, até alguns dias do evento.

De acordo com a cartilha elaborada pela Secretaria Estadual da Defesa Civil do Ceará (2008, p. 13), há diversas ações preventivas a serem executadas, tais como: acrescentar uma ripa extra entre as já existentes no telhado das casas, estudar os locais de maior segurança da residência, não espalhar boatos de qualquer espécie a respeito de desastres e etc. Já dentre os procedimentos durante os terremotos encontram-se os seguintes: proteger a cabeça com livros e tábuas, manter-se tranquilo, não permanecer em sacadas e janelas e informar imediatamente a Defesa Civil sobre as características do evento (DEFESA CIVIL, 2008). O documento ainda aborda situações diversas, como estar em locais com muitas pessoas, ao ar livre e em prédios.

A conduta defendida no site da instituição representante do Maranhão (DEFESA CIVIL, 2017) restringese apenas aos procedimentos a serem seguidos após o tremor, tendo como exemplos: "Afastar-se de móveis que podem tombar e esconder-se sob uma mesa ou outro móvel resistente e não sair desesperadamente" e "Fechar o registro de gás e retirar os fios da tomada [...] Abrir portas e janelas para assegurar uma saída de emergência.” Há indicações de como proceder em diversas situações, como dentro 
de automóveis, em locais abertos, e também após 3 dias do sismo, sendo que deste último item tem-se o seguinte:

Verificar a segurança da família e ficar atento para os abalos sísmicos secundários; Não se aproximar de casas semi destruídas. Chamar os vizinhos e dependendo das condições, abrigar-se a pé; Colaborar com as atividades de extinção de incêndio, resgate e salvamento de pessoas machucadas; Usar a água e comida estocada para emergência. Tomar cuidado com boatos e assegurar informações corretas. (DEFESA CIVIL, 2017)

\section{CONSIDERAÇÕES FINAIS}

A temática dos desastres naturais causados pelos terremotos é relativamente pouco discutida no Brasil, principalmente devido ao fato de que o país não se situa em zonas limítrofes entre placas tectônicas. Contudo, a partir dos anos 1990, os estudos sobre as falhas neotectônicas alertam sobre esta temática. Dentre estes estudos destaca-se o de Saadi, sobre a Neotectônica da plataforma brasileira, publicado em 1993.

No entanto, devido a falta de conhecimento a respeito do tema por boa parte da população, é importante que estes cenários de risco sejam levados em consideração pela Secretaria Nacional de Defesa Civil na elaboração de planos de emergência, e sobretudo na criação e divulgação de Cartilhas de Prevenção de Desastres, visando auxiliar a população no proceder durante os eventos sísmicos e mitigar possíveis desastres.

Sugerimos que, assim como é proposto por órgãos oficiais do Estado (BRASIL, 2003) para eventos ligados a inundações e movimentos de massa, é relevante também que sejam aplicados programas educacionais nas escolas, visando assistir as comunidades mais vulneráveis, informando sobre o fenômeno e comportamento mais adequado em determinadas circunstâncias quando da manifestação de um evento sísmico.

Apesar de a ABNT ter uma normativa técnica que regulamenta os requisitos mínimos para a construção civil no que diz respeito a abalos sísmicos e ainda que a presença da Rede Sismográfica Nacional possa monitorar a ação sísmica em território nacional, a população não está preparada caso ocorra um evento de magnitude pequena a moderada. Deve-se desenvolver amplamente cartilhas de Prevenção pela Defesa Civil em todos os Estados da Federação e projetos nas escolas. Contudo, afirmamos concomitantemente que deve ser combatida a visão sensacionalista sobre a ocorrência de terremotos extremos no país $(\geq$ $8 M w)$, sendo que é geologicamente impossível. 


\section{REFERÊNCIAS}

ASSOCIAÇÃO BRASILEIRA DE NORMAS TÉCNICAS. NBR 15421: projeto de estruturas resistentes a sismos procedimento. Rio de Janeiro, 2006.

APOLO11. Falhas geológicas brasileiras - onde estão localizadas? In: Apolo11: espaço - ciências - fenômenos naturais, 2007. Disponível em: <http://www.apolo11.com/curiosidades.php?posic=dat_20071211-092620.inc〉. Acesso em: 11 nov. 2016.

BRASIL. Ministério da Integração Nacional. Manual de Desastres. Brasília: 2003. Volume I. Disponível em: <http://www.mi.gov.br/c/document_library/get_file?uuid=47a84296-d5c0-474d-a6ca8201e6c253f4\&groupId=10157>. Acesso em: 23 jan. 2017.

CERRI, L. E. da S. AMARAL, C. P. do. Riscos Geológicos. In: OliVEIRA, A. M. dos S. BRITO, S. N. A. de. Geologia de Engenharia. São Paulo: Associação de Geologia de Engenharia, 1998.

CORONEL PAIM. Famílias afetadas por terremoto em Itacarambi (MG) recebem novas casas. 2008. In: Municípios mineiros, 2008. Disponível em: <http://itacarambimg.blogspot.com.br/2008/05/famlias-afetadas-porterremoto-em.html>. Acesso em: 10 nov. 2016.

DEFESA CIVIL. Tremor de Terra: saiba como agir. Ceará: 2008. Disponível em: <https://drive.google.com/file/d/0B2nxZNBXnLuqT2w2dWQ2R0M1N0k/view>. Acesso em: 23 jan. 2017.

DEFESA CIVIL. Abalos Sísmicos. Maranhão: 2017. Disponível em: <http://www.defesacivil.ma.gov.br/abalossismicos/>. Acesso em 28 de Janeiro de 2017. Acesso em: 23 jan. 2017.

HIRUMA, S. T. RICCOMINI, C. MODENESI-GAUTTIERI, M. C. Neotectônica no Planalto de Campos do Jordão, SP. In: Revista Brasileira de Geociências, vol. 31, 2001. Disponível em: <https://www.researchgate.net/profile/Claudio_Riccomini/publication/34283968_Neotectonica_no_planalto_de_Ca mpos_do_Jordao_SP/links/0fcfd50dc84532a776000000.pdf>. Acesso em: 16 jan. 2017.

INGV. Magnitudo Richter (MI) magnitudo momento (Mw): perché possono essere differenti? In: INGV - Istituto Nazionale di Geofisica e Vulcanologia. Disponível em: <http://www.ingv.it/ufficio-stampa/faq/terremoti/magnitudorichter-ml-e-magnitudo-momento-mw-perche-possono-essere-differenti>. Acesso em: 27 jan. 2017.

LOPES, A. E. de V. NUNES, L. C. Intensidades sísmicas de terremotos: formulação de cenários sísmicos no Brasil. Revista USP, São Paulo, no 91, 2011. p. 90-102.

OBSIS. Observatório Sismológico da Universidade de Brasília. In: OBSIS, 2016. Disponível em: <http://www.obsis.unb.br/sisbra>. Acesso em: 13 fev. 2017.

PALACIOS, J. D. CHUQUISENGO, O. FERRADAS, P. Gestión de riesgo en los gobiernos locales. Lima: Soluciones Prácticas - ITDG, 2005.

PENA, R. F. A. Os maiores terremotos da história. In: Mundo Educação, 2016. Disponível em: <http://mundoeducacao.bol.uol.com.br/geografia/os-maiores-terremotos-historia.htm〉. Acesso em: 11 nov. 2016.

RSBR. Estações Instaladas. In: Rede Sismográfica Brasileira, 2017. Disponível em: <http://www.rsbr.gov.br/estacoes_instaladas.html>. Acesso em: 14 jan.2017.

SAADI, A. Neotectônica da Plataforma Brasileira: esboço e interpretação preliminares. In: GEONOMOS, Revista do Centro de Pesquisa Professor Manoel Teixeira da Costa, Instituto de Geociências - UFMG, v. 1, 1993. Disponível em: <http://www.igc.ufmg.br/portaldeperiodicos/index.php/geonomos/article/view/233>. Acesso em: 11 nov. 2016.

SIMÕES, M. Hipocentro e epicentro. Portugal, 2013. Disponível em: <http://qualeoteulimite.blogspot.com.br/2013/06/hipocentro-e-epicentro.html>. Acesso em: 11 nov. 2016.

VALDATI, J. Riscos e Desastres Naturais: a área de risco de inundação da sub-bacia do rio da Pedra - Jacinto Machado/SC. 2000. Dissertação (Mestrado em Geografia) - Universidade Federal de Santa Catarina, 2000.

USGS. Earthquake Glossary - magnitude. In: US Geological Survey - USGS: science for a changing word, 2016. Disponível em: <https://earthquake.usgs.gov/learn/glossary/?term=magnitude〉. Acesso em: 16 fev. 2017. 


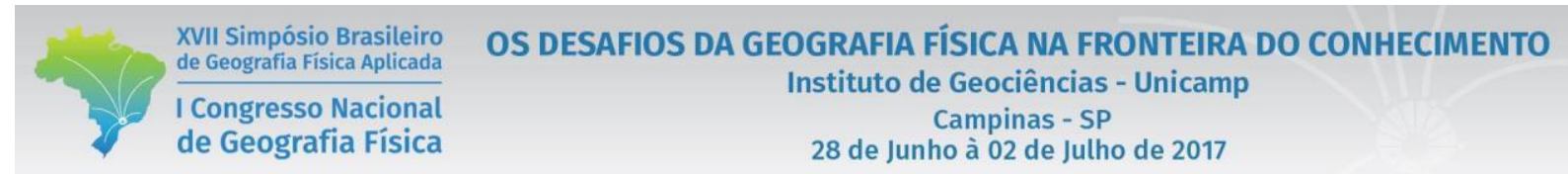

WINCANDER. R.; MONROE, J. S. PETERS, K. Fundamentos de Geologia. Tradução e adaptação: CARNEIRO, M. A. São Paulo: Cengage Learning, 2009.

WOO, Wang-chun. On Earthquake Magnitudes. In: Hong Kong Observatory, 2012. Disponível em: <http://www.weather.gov.hk/education/edu02rga/article/ele-EarthquakeMagnetude_e.htm\#q3>. Acesso em: 16 fev. 2017. 